\title{
Indacaterol Inhibits Tumor Cell Invasiveness and MMP-9 Expression by Suppressing IKK/NF-kB Activation
}

\author{
Su Ui Lee ${ }^{1,4}$, Kyung-Seop Ahn ${ }^{1,4}$, Min Hee Sung ${ }^{1}$, Ji-Won Park ${ }^{1}$, Hyung Won Ryu ${ }^{1}$, Hyun-Jun Lee ${ }^{2}$, \\ Sung-Tae Hong ${ }^{3, *}$, and Sei-Ryang $\mathrm{Oh}^{1, *}$
}

\begin{abstract}
The $\beta_{2}$ adrenergic receptor (ADRB2) is a G protein-coupled transmembrane receptor expressed in the human respiratory tract and widely recognized as a pharmacological target for treatments of asthma and chronic obstructive pulmonary disorder (COPD). Although a number of ADRB2 agonists have been developed for use in asthma therapy, indacaterol is the only ultra-long-acting inhaled $\beta_{2}$-agonist (LABA) approved by the FDA for relieving the symptoms in COPD patients.

The precise molecular mechanism underlying the pharmacological effect of indacaterol, however, remains unclear. Here, we show that $\beta$-arrestin-2 mediates the internalization of ADRB2 following indacaterol treatment. Moreover, we demonstrate that indacaterol significantly inhibits tumor necrosis factor- $\alpha$ (TNF- $\alpha$ )-induced NF-kB activity by reducing levels of both phosphorylated-IKK and $-I_{K} B \alpha$, thereby decreasing NF- $\mathrm{KB}$ nuclear translocation and the expression of MMP-9, an NF-KB target gene. Subsequently, we show that indacaterol significantly inhibits TNF- $\alpha / N F-\kappa B-i n d u c e d$ cell invasiveness and migration in a human cancer cell line. In conclusion, we propose that indacaterol may inhibit NF$\kappa B$ activity in a $\beta$-arrestin2-dependent manner, preventing further lung damage and improving lung function in COPD patients.
\end{abstract}

\section{INTRODUCTION}

Asthma and chronic obstructive pulmonary disorder (COPD) are two diseases that commonly cause inflammation and hyperactivity in the airways. Asthma is associated with intermittent and

\footnotetext{
${ }^{1}$ Natural Medicine Research Center, ${ }^{2}$ Targeted Medicine Research Center, Korea Research Institute of Bioscience and Biotechnology, Chungbuk 363-883, Korea, ${ }^{3}$ Department of Biological Sciences, Korea Advanced Institute of Science and Technology, Daejeon 305-701, Korea, ${ }^{4}$ These authors contributed equally to this work.

*Correspondence: seiryang@kribb.re.kr (SRO); mogwai@kaist.ac.kr (STH)
}

Received 2 April, 2014; revised 8 July, 2014; accepted 15 July, 2014; published online 18 August, 2014

Keywords: ADRB2, indacaterol, invasion, MMP-9, NF-kB reversible airway obstruction, whereas COPD results in generally progressive and irreversible lung damage such as chronic bronchitis and emphysema. Moreover, the prevalence of COPD in patients diagnosed with lung cancer is $40-70 \%$ (Loganathan et al., 2006). These mean that COPD has also been associated with worsening severity stages of lung function failure (Sekine et al., 2012; Vestbo et al., 1996). Given that COPD causes progressive damage in the lungs, it is possible that chemicals or drugs that improve lung function may be good candidates for COPD treatment. Combination treatments using various bronchodilators with distinct mechanisms of action have provided good outcomes in the management of COPD in the past (Tashkin and Ferguson, 2013). However, the development of monotherapeutics with good efficacy and safety is necessitated by the need to offer patients more convenient and effective treatments.

The $\beta_{2}$ adrenergic receptor ( $\beta_{2}$ adrenoreceptor; ADRB2) is a transmembrane $\mathrm{G}$ protein-coupled receptor (GPCR) located on airway smooth muscle cells. Since ADRB2 activation facilitates respiration, the receptor is widely recognized as a pharmacological target for controlling bronchoconstriction associated with asthma and COPD (Johnson, 2006). For this reason, ADRB2 agonists have been developed as drugs to relieve dyspnea in severe asthma and COPD patients. These drugs are classified into two main classes: short-acting $\beta_{2}$-adrenoceptor agonists (SABAs) and long-acting $\beta_{2}$-adrenoceptor agonists (LABAs), according to their duration of action and the degree of agonism. In particular, LABAs such as formoterol and salmeterol effectively relieve symptoms and improve lung functions in patients with COPD receiving combination treatment incorporating a corticosteroid (Welte, 2009). However, there are major limitations in using the corticosteroid-combined treatments for COPD patients, since these therapies are not always completely effective and have side effects such as osteoporosis and pneumonia (Hanania et al., 1995). Therefore, recent studies have increasingly focused on the development of novel LABAs with longer duration of action (Tashkin and Ferguson, 2013). Interestingly, indacaterol (Fig. 1A, an ultra-LABA) has been recently approved by U. S. Food and Drug Administration (FDA) for use as a oncedaily, inhaled monotherapy providing symptom relief for COPD patients (Naline et al., 2007). However, the molecular mechanism underlying the pharmacological effects of indacaterol remains unclear.

Tumor necrosis factor- $\alpha$ (TNF- $\alpha$ ) is a key cytokine for activating NF- $\mathrm{kB}$ signaling that is involved in a number of inflammatory 
A

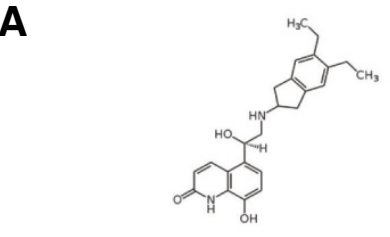

B

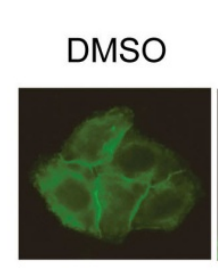

Indacaterol $(5 \mu \mathrm{M})$

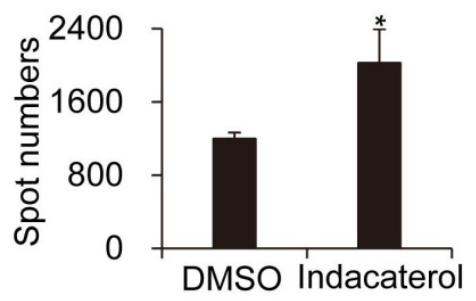

C

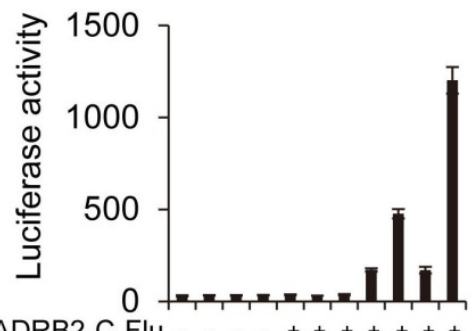

ADRB2-C-Flu - . - + + + + + ++

$\beta$-arr1-N-Flu $++\ldots+\ldots++\cdots$

$\beta$-arr2-N-Flu - - + + . + +

Indacaterol $(5 \mu \mathrm{M}) \ldots+\cdots+++++$
Fig. 1. Indacaterol-induced interaction between ADRB2 and $\beta$-arrestins. (A) The structure of indacaterol. (B) Indacaterol induces ADRB2 internalization in HeLa cells stably expressing ADRB2GFP. Cellomics high-content screening instrument was used to acquire image and analyze ADRB2-GFP signals (upper and lower panels, respectively). Data are representative of three independent experiments $\left({ }^{*} p<0.05\right)$. (C) HEK293 cells were transiently transfected with ADRB2-C-Luc, ßarr1-N-Luc, and $\beta$ arr2-N-Luc, as described in "Materials and Methods". Twenty-four hours following transfection, cells were treated for $0.5 \mathrm{~h}$ with $5 \mu \mathrm{M}$ indacaterol and luciferase activity was measured. lung diseases such as asthma and COPD (Matera et al., 2010). In effect, animal models overexpressing TNF- $\alpha$ exhibit an induction of pathological features associated with COPD, such as inflammatory cell infiltration into the lungs, pulmonary fibrosis, and emphysema (Lundblad et al., 2005). Generally, increased TNF- $\alpha$ activates the IKB-kinase (IKK) complex, composed of two kinases (IKK $\alpha$ and $\mathrm{IKK} \beta$ ) and a regulatory subunit NF-KBessential modulator (NEMO). Activated IKK subsequently stimu-

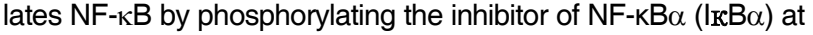
Ser32 and Ser36, resulting in $\mathrm{I}_{\mathrm{K}} \mathrm{B} \alpha$ ubiquitination and degradation (Ghosh et al., 1998). NF-kB, a heterodimer of p65 and p50, is one of the most important transcription factors and plays an essential role in most immune and inflammatory responses, as well as in regulation of matrix metalloproteinase-9 (MMP-9, also called gelatinase $\mathrm{B}, 92 \mathrm{kDa}$ ) production.

Interestingly, MMP-9, induced by the TNF- $\alpha$ signal, is recognized as a potential target gene involved in emphysema associated with COPD (Finlay et al., 1997), since selective inhibitors of MMP-9 prevent smoke-induced increases in small airway wall thickness in a guinea pig model (Churg et al., 2007) ,and are also known to be an important regulatory molecule involved in the regulation of migration and invasion behavior of various cancer cells (Ling et al., 2011). Furthermore, recent studies showed that ADRB2-stimulated $\beta$-arrestins binds to $I_{k B} \alpha$ to inhibit NF- $\mathrm{kB}$ activity (Gao et al., 2004). Taken together, these reports suggest that indacaterol may associate with TNF- $\alpha$ signaling components and have led us to focus on the effect of indacaterol on the NF-kB pathway.

In our current study evaluating the molecular mechanism of the pharmacological effect of indacaterol, we show that $\beta$ arrestin2 ( $\beta$-arr2) is required to mediate the internalization of ADRB2 by indacaterol treatment. Moreover, we demonstrate that indacaterol treatment significantly inhibits TNF- $\alpha$-induced MMP-9 expression and its enzymatic activity by blocking the IKK/NF-кB activation pathway. Subsequently, we show that indacaterol significantly inhibits TNF- $\alpha$-induced migration and invasion of human fibrosarcoma cells. These results collectively suggest that indacaterol is a promising candidate drug with potential for use in improving lung function in the treatment of
COPD by inhibiting the expression of NF-кB-response genes such as MMP-9.

\section{MATERIALS AND METHODS}

Cell culture and reagents

Indacaterol was purchased from Zhiyu Biotechnology (China). The drug was dissolved in DMSO for cell culture experiments. TNF- $\alpha$ (Sigma, USA) was used at $10 \mathrm{ng} / \mathrm{ml}$ HeLa (CCL-2), HEK293 (CRL-1573), and HT1080 (CCL-121) cells were obtained from the American Type Culture Collection. Cells were maintained in Dulbeccoed in Dulbeccotential for use EM, HyClone, USA) supplemented with $10 \%$ fetal bovine serum (100 units/ml penicillin and 100 andml streptomycin) (FBS, Gibco) at $37^{\circ} \mathrm{C}$, in a humidified $5 \% \mathrm{CO}_{2}$ atmosphere.

Establishment of a stable cell line for high-content assay Human ADRB2 fused to green fluorescent protein (GFP) was cloned into pIRESpuro3 (Clontech, USA) vector and transfected into HeLa cells using Lipofectamine 2000 (Invitrogen, USA) according to the manufacturer's protocols. Transfected cells were selected as previously described (Lee et al., 2013) and spot formation of ADRB2-GFP signal was analyzed using Spot Detector BioApplication assay with the Cellomics ${ }^{\circledR}$ ArrayScan ${ }^{\circledR}$ VTI HCS reader (ThermoFisher, USA). Significance was determined by Student's $t$-test, with differences considered significant with $p<0.01$.

Protein-protein interaction (PPI) assay with split luciferase Human ADRB2 was amplified from human cDNA library and cloned into pcDNA3.1-CLuc containing C-terminal fragment of firefly luciferase (aa.1-416). Rat $\beta$-arrestin1 ( $\beta$-arr1) and $\beta$ arrestin2 ( $\beta$-arr2) were cloned into pcDNA3.1-NLuc containing the N-terminal fragment of firefly luciferase (aa. 398-550) (Lee et al., 2013). PCR primers were synthesized by Bioneer, Korea. All clones were verified by sequencing (Solgent, Korea).

To measure luciferase activity, cells were plated $\left(1 \times 10^{4}\right.$ cells/well) in 96-well plates and the plasmids were transfected using Lipofectamine 2000 (Invitrogen) according to the manufac- 
ture's instruction. Luciferase activity was determined by OneGlo Luciferase Assay kit (Promega, USA). Cells treated with DMSO vehicle were used as a control.

\section{Evaluation of mRNA expression levels}

Total RNA was isolated using TRIzol reagent (Invitrogen), and first-strand cDNA was synthesized using Omniscript Reverse Transcriptase (Qiagen, USA). SYBR green-based quantitative PCR amplification was performed with CFX 96 Real-Time RTPCR Detection system (Bio-Rad) and the SYBR Green Master Mix (Bio-Rad). All reactions were run in triplicate. Data were expressed as GAPDH-normalized $2^{-\triangle \Delta C T}$ values. Significance was determined by Student's $t$-test, and differences were considered significant with $p<0.01\left(^{*}\right)$ and $p<0.001\left(^{* *}\right)$.

\section{Western blot analysis}

HT1080 cells $\left(5 \times 10^{5}\right.$ cells/well) were seeded on 6 -well plates and incubated for $12 \mathrm{~h}$. The incubation medium was changed to DMEM supplemented with $0.1 \%$ FBS, 100 units $/ \mathrm{ml}$ penicillin, and $100 \mu \mathrm{g} / \mathrm{ml}$ streptomycin. Following $16 \mathrm{~h}$ of incubation, cells were pretreated with a range of concentrations of indacaterol for $2 \mathrm{~h}$ and treated with TNF- $\alpha(10 \mathrm{ng} / \mathrm{ml})$ for $0.5 \mathrm{~h}$. Proteins were homogenized in ice-cold buffer containing $50 \mathrm{mM}$ Tris- $\mathrm{HCl}(\mathrm{pH}$ 8.0), $5 \mathrm{mM}$ EDTA, $150 \mathrm{mM} \mathrm{NaCl}, 1 \% \mathrm{NP}-40,0.1 \%$ sodium dodecyl sulfate (SDS), $1 \mathrm{mM}$ PMSF, and one protease inhibitor cocktail tablet (Roche, Germany) and centrifuged at 10,000 $\times g$ for $15 \mathrm{~min}$ at $4^{\circ} \mathrm{C}$. The supernatant was used as the cytoplasmic protein (Cyto) fraction and nuclear proteins (Nuc) were extracted using the NucBuster Protein Extraction kit (Novagen, Germany). Protein samples $(20-30 \mu \mathrm{g})$ were prepared and loaded as previously described (Lee et al., 2010). At least $30 \mu \mathrm{g}$ of whole-cell lysate and $20 \mu \mathrm{g}$ of Cyto/Nuc fractions per lane were loaded for western blot analysis. Anti-GAPDH, anti-HDAC1, and anti-PCNA antibodies were purchased from Santa Cruz Biotechnology,

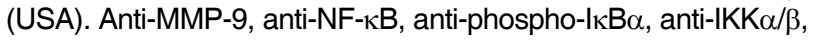
and anti-IKK $\beta$ antibodies were obtained from Cell Signaling Technology (USA). Protein bands were visualized using a LAS4000 luminescent image analyzer and their intensity quantified by densitometry using Fuji Multi Gauge software.

\section{Zymography assay}

The enzyme activities of MMP-9 in conditioned medium were determined by gelatin zymography protease assay. Briefly, cells $\left(2 \times 10^{5}\right.$ cells/well) were seeded in 6-well plates and allowed to grow to $80 \%$ confluency. The cells were then maintained in serum-free medium for $12 \mathrm{~h}$ prior to designated treatments with indacaterol and TNF- $\alpha$ for $24 \mathrm{~h}$. Conditioned media were collected, cleared by centrifugation, and mixed with 2hy protease assay. Briefly, cells $\left(2 \times 10^{5}\right.$ cells/well) were seeded in 6-well plates and allowed to grow to $80 \%$ confluency. The cells were then maintained in serum-freebated in renaturation buffer $(2.5 \%$ Triton X-100) with gentle agitation at room temperature to remove SDS, followed by incubation in developing buffer $(50 \mathrm{mM}$ Tris-HCl buffer, $\mathrm{pH} 7.4$, and $10 \mathrm{mM} \mathrm{CaCl}_{2}$ ) overnight at $37^{\circ} \mathrm{C}$ to allow digestion of gelatin. Gels were then stained with Brilliant Blue R (Sigma-Aldrich) until clear bands corresponding to gelatin digestion appeared.

\section{Cell invasion assay}

Cell invasion assay was conducted using cell culture inserts (BD Biosciences, USA) according to the manufacturer's instructions. Briefly, culture inserts were coated with $200 \mu \mathrm{g} / \mathrm{ml}$ of Matrigel (BD Biosciences) for $2 \mathrm{~h}$. Cells $\left(1 \times 10^{4}\right)$ suspended in $0.25 \mathrm{ml}$ of $0.2 \%$ FBS DMEM were added to the upper chamber of the Matrigel-coated filter inserts. After treatment with $10 \mu \mathrm{M}$ indacaterol for $2 \mathrm{~h}, 0.75 \mathrm{ml}$ of $10 \%$ FBS DMEM containing $10 \mathrm{ng} / \mathrm{ml}$ of TNF$\alpha$ was added to the bottom well as a chemoattractant. The chambers were then incubated for $4 \mathrm{~h}$. After incubation, cells on the upper side of the chamber were removed using cotton swabs, and cells that had migrated were fixed and stained with methanol containing $0.5 \%$ crystal violet powder. Invading cells were enumerated under a light microscope at $20 x$ objective (Olympus) and the number of cells per field in representative areas was counted. Experiments were performed in triplicates.

\section{Wound healing assay}

A total of $5 \times 10^{4}$ cells were seeded onto both sides of a culture insert (ibidi, Germany). After treatment with $10 \mu \mathrm{M}$ indacaterol for $2 \mathrm{~h}$, the culture insert was removed carefully and $10 \% \mathrm{FBS}$ DMEM containing $10 \mathrm{ng} / \mathrm{ml}$ of TNF- $\alpha$ was added to the dish. Cells were incubated for $8 \mathrm{~h}$. The zone of wound healing and migrated cells was observed using light microscopy (Olympus).

Statistical analysis

Data are presented as means \pm standard deviation. Significance was determined by Student's $t$-test, and differences were considered significant at $\left.p<0.05\left(^{*}\right), p<0.01{ }^{(*}\right)$, and $\left.p<0.001{ }^{* \star *}\right)$.

\section{RESULTS}

Indacaterol preferentially enhances $\beta$-arr2-mediated ADRB2 internalization

Prior to identifying the mechanism of indacaterol (Fig. 1A) as an agonist of ADRB2, we examined whether indacaterol induces the internalization of ADRB2 (typically resulting from agonism of ADRB2). To visualize and quantitatively analyze the internalization of ADRB2, we generated a stable HeLa cell line expressing GFP-tagged ADRB2 (ADRB2-GFP) and used ArrayScan (Cellomics, USA) microtiter plate imaging system to quantify cellular fluorescence in whole cells. This assay system was shown to be responsive to indacaterol (Naline et al., 2007), as well as other established ADRB2 agonists such as Isoproterenol (Barnes and Pride, 1983), salbutamol (Ball et al., 1991; Cullum et al., 1969), formoterol (van der Molen et al., 1997), and salmeterol (Ball et al., 1991) (Supplementary Fig. 1).

Following treatment with $5 \mu \mathrm{M}$ indacaterol or vehicle for $0.5 \mathrm{~h}$, cells were fixed and the images of ADRB2 internalization were acquired (Fig. 1B, upper panels). Spot formation of internalized ADRB2-GFP was analyzed quantitatively using Cellomics BioApplication analysis software (Spot Detector). The number of intracellular GFP spots was significantly increased following indacaterol treatment (Fig. 1B, lower panel). This indicates that indacaterol initiates the intracellular signal and enhances the internalization of ADRB2 as an agonist of ADRB2.

Generally, the internalization of ligand-activated GPCR is triggered by both GRK (GPCR kinase)-mediated receptor phosphorylation and subsequent $\beta$-arrestins binding to the intracellular phosphate groups (Lefkowitz and Shenoy, 2005; Shenoy and Lefkowitz, 2003). Therefore, we checked whether indacaterol treatment affects the interaction between $\beta$-arrestins and ADRB2. To achieve this, we developed an assay to measure proteinprotein interactions (PPI) between ADRB2 and $\beta$-arrestin using bimolecular luminescence complementation method (BiLC) based on the complemented luciferase activity, as described in the "Materials and Methods". Next, both ADRB2 fused to the Cterminal region of firefly luciferase (ADRB2-CLuc) and $\beta$ arrestin1 or 2 fused to the $\mathrm{N}$-terminal region of firefly luciferase (NLuc- $\beta$-arr1/2) were transiently co-expressed in HEK293 cells. Co-expressed ADRB2-CLuc and NLuc- $\beta$-arr1/2 exhibited complemented luciferase activity, which was augmented by treat- 


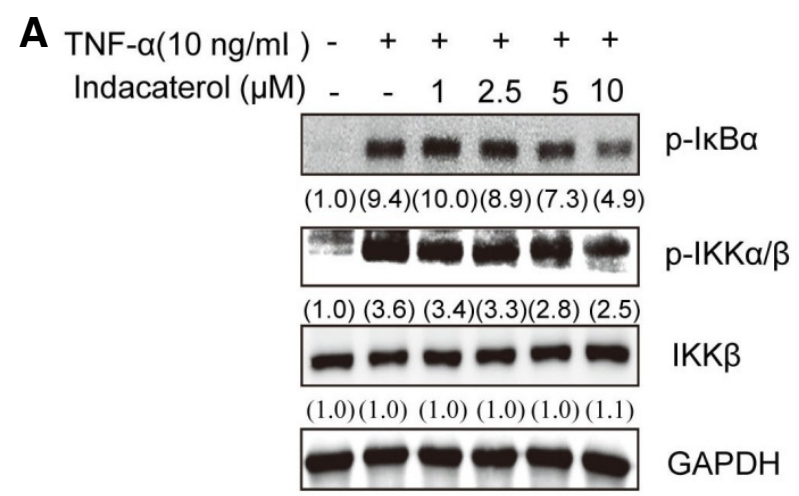

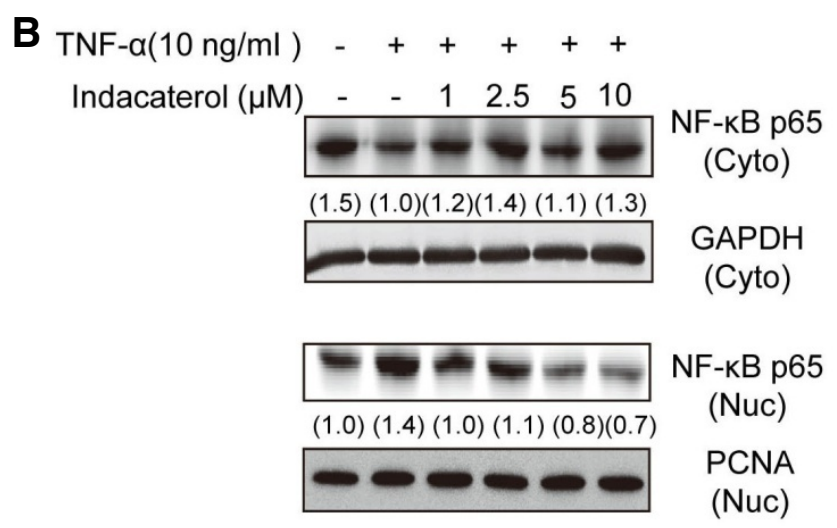

Fig. 2. Inhibition of NF-kB signaling by indacaterol. HT1080 cells $\left(5 \times 10^{5}\right.$ cells per well) were seeded and incubated for $12 \mathrm{~h}$. The medium was exchanged for DMEM supplemented with $0.1 \%$ FBS (100 units $/ \mathrm{ml}$ penicillin and $100 \mu \mathrm{g} / \mathrm{ml}$ streptomycin). After $16 \mathrm{~h}$, cells were pretreated with the corresponding concentration of indacaterol for $2 \mathrm{~h}$ and treated with TNF- $\alpha(10 \mathrm{ng} / \mathrm{ml})$ for $0.5 \mathrm{~h}$. (A) Total cell lysates were analyzed using antibodies against phosphorylated $\mathrm{I} \mathrm{KB} \alpha$, phosphorylated IKK $\alpha / \beta$, IKK $\beta$, and GAPDH. (B) Cells were subfractionated into nuclear and cytoplasmic extracts. Antibodies against p65 NF-KB (top panel) and GAPDH (upper middle panel) were used for cytoplasmic fraction. Antibodies against p65 NF-kB (lower middle panel) and PCNA (bottom panel) were used as the nuclear fraction. Numbers in parentheses represent the intensities of bands, expressed relative to the control, estimated using Multi Gauge software version 3.0. The results shown are representative of three independent experiments.

ment with $5 \mu \mathrm{M}$ indacaterol (Fig. 1C). Notably, we found that $\beta$ arr2 coupled to ADRB2 following indacaterol treatment induces much higher level of ADRB2 internalization compared to $\beta$-arr1 (Fig. 1C, lanes 9 and 11). These results show that indacaterolinduced internalization of ADRB2 is primarily mediated by $\beta$-arr2.

Indacaterol inhibits TNF- $\alpha$-activated IKK/NF-KB signaling Recent studies have found that $\beta$-arrestins may play an important role in inhibiting NF- $\mathrm{KB}$ pathway (Gao et al., 2004; Witherow et al., 2004). Since activated NF-kB amplifies airway and mucosal inflammation and exacerbates COPD (Watanabe et al., 2004), we tested whether indacaterol-induced $\beta$-arr2 internaliza-

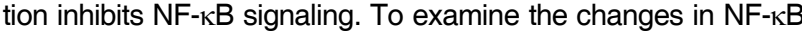
signaling, we treated $\mathrm{HT} 1080$ cells with $\mathrm{TNF}-\alpha$, a potent activator of NF-kB, and analyzed protein expression using western blot methods with antibodies specific for phosphorylated IKK $\alpha / \beta$, $\mathrm{IKK} \beta$, phosphorylated $\mathrm{I}_{\kappa} \mathrm{B} \alpha$, and NF-kBp65. As shown in Fig. $2 \mathrm{~A}$, TNF- $\alpha$ induced the phosphorylation of $I_{\kappa} B \alpha$ and $I K K \alpha / \beta$ (the upstream activators of $\mathrm{NF}-\mathrm{kB}$ ), but indacaterol pretreatments (both 5 and $10 \mu \mathrm{M}$ ) under the same conditions suppressed their phosphorylation. Moreover, consistent with this result, TNF- $\alpha-$ induced NF- $\mathrm{KB}$ nuclear translocation was also largely inhibited by pretreatments with 5 and $10 \mu \mathrm{M}$ indacaterol (Fig. 2B). Therefore, our results suggest that indacaterol may inhibit NF-kBdependent target gene expression by reducing the activity of $\mathrm{NF}-\kappa \mathrm{B}$ upstream activators.

Indacaterol inhibits TNF- $\alpha$-induced MMP-9 expression and activity in human fibrosarcoma HT1080 cells.

TNF- $\alpha$-stimulated NF- $\mathrm{KB}$ activation induces the expression of MMP-9, a potential drug target for treatment of COPD (Muroski et al., 2008). We therefore tested whether indacaterol, which inhibits TNF- $\alpha$-stimulated NF- $\kappa B$ signaling, also down-regulates the expression of MMP-9. Prior to the experiment, we verified that cell growth in human fibrosarcoma HT1080 cells, which constitutively express MMP-9, is not affected by indacaterol at concentrations up to $10 \mu \mathrm{M}$ (data not shown). We subsequently assayed whether MMP-9 mRNA expression is down-regulated by indacaterol using quantitative real-time PCR. TNF- $\alpha$-induced MMP-9 mRNA expression was significantly suppressed by pretreatment with indacaterol in the 2.5 to $10 \mu \mathrm{M}$ range (Fig. $3 \mathrm{~A}$ ), whereas very little effect was observed on the expression of MMP-2 (data not shown).

Consistent with this result, indacaterol pretreatment in the concentration range between 2.5 and $10 \mu \mathrm{M}$ also suppressed TNF- $\alpha$-induced MMP-9 enzyme activity and decreased its protein levels in a dose-dependent manner, which was assayed using gelatin zymography and western blot approaches, respectively (Fig. 3B). Taken together, these findings indicate that indacaterol inhibits MMP- 9 activity by suppressing NF- $\mathrm{kB}-$ mediated MMP-9 transcription.

Indacaterol inhibits TNF- $\alpha$-induced invasion and migration of human fibrosarcoma cells

Since MMP-9 expression enhances the invasion and metastasis of tumor cells (Klein et al., 2004), we tested whether indacaterol suppression of NF-kB-mediated MMP-9 transcription has any anti-invasion effects in human fibrosarcoma HT1080.

First, we investigated the effect of indacaterol on cell invasion activity of fibrosarcoma using a transwell invasion assay. For quantitative analysis of cell invasiveness, the images of fibrosarcoma cells migrating across Matrigel were acquired (Fig. 4A) and the number of migrating cells was counted using Image $J$ software (Fig. 4B). This quantitative assessment showed that cell migration of indacaterol-treated fibrosarcoma is significantly reduced (to approximately half of the level observed in untreated controls). This result showed that indacaterol could substantially suppress cell invasion activity of human fibrosarcoma by reducing MMP-9 expression and its activity.

Furthermore, indacaterol inhibited migration of a malignant mesenchymal tumor cell in wound healing assay, with TNF- $\alpha-$ induced HT1080 cell migration inhibited in the zone of wound healing by indacaterol treatment (Fig. 4C). Altogether, these data demonstrated that indacaterol suppressed migration related to MMP-9 expression and activity. 
A

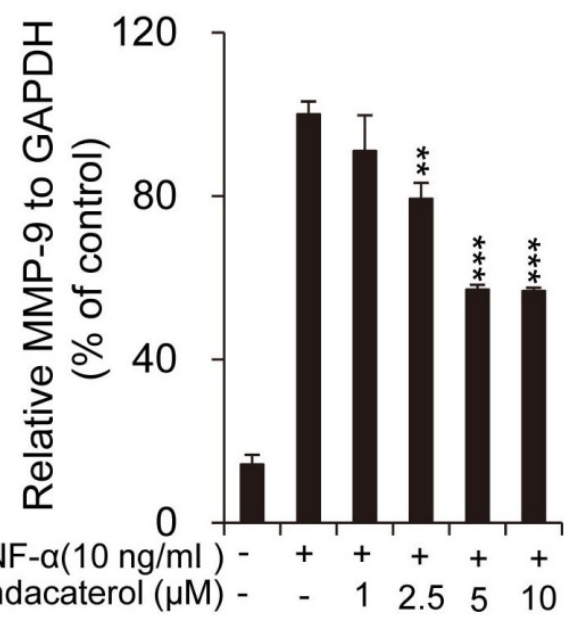

B

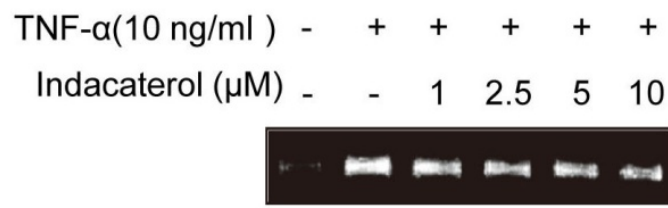

MMP-9 (zymo.)

$(1.0)(13.3)(11.0)(9.5)(9.6)(8.6)$

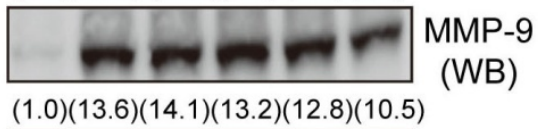

(WB)

HDAC1

(WB)

Fig. 3. Inhibition of MMP-9 expression and activity by indacaterol. (A) The effect of indacaterol on the expression of MMP-9 mRNA was assessed using quantitative real-time PCR. HT1080 cells $\left(1 \times 10^{5}\right.$ cells per well) were seeded on 24 -well plates and incubated for $12 \mathrm{~h}$. Following incubation, the medium was changed to DMEM supplemented with $0.1 \%$ FBS (100 units $/ \mathrm{ml}$ penicillin and $100 \mu \mathrm{g} / \mathrm{ml} \mathrm{streptomycin).} \mathrm{After} 16 \mathrm{~h}$,

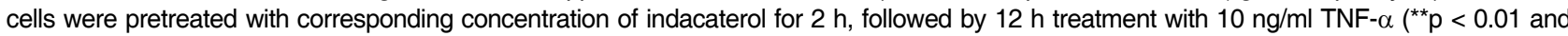
$\left.{ }^{* * *} \mathrm{p}<0.001\right)$. (B) The effect of indacaterol on the expression and activity of MMP-9 protein was assayed using gelatin zymography and Western blot, respectively. Cells $\left(2 \times 10^{5}\right.$ cells per well) were seeded in 6 -well plates and allowed to grow to $80 \%$ confluency. The cells were then maintained in serum-free medium for $12 \mathrm{~h}$ prior to treatments with indacaterol and TNF- $\alpha$ for $24 \mathrm{~h}$. Numbers in parentheses indicate the intensity of band, expressed relative to the controls, estimated using Multi Gauge software version 3.0.

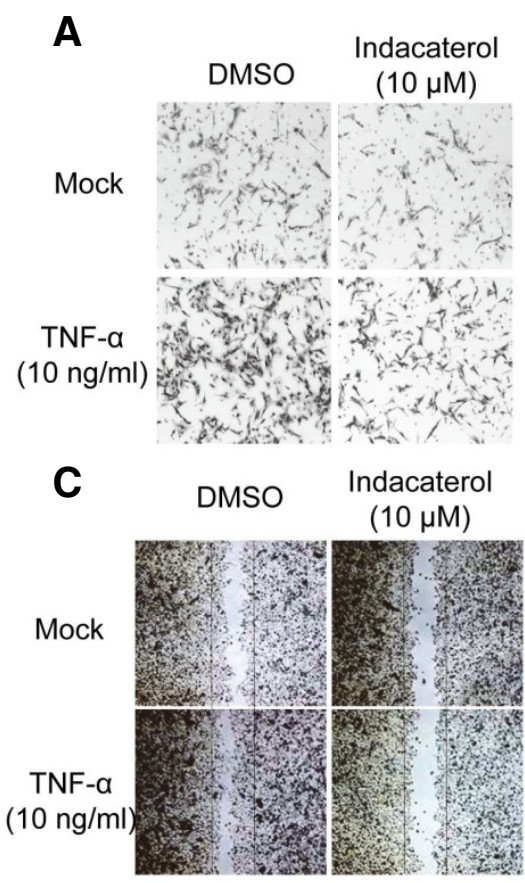

B

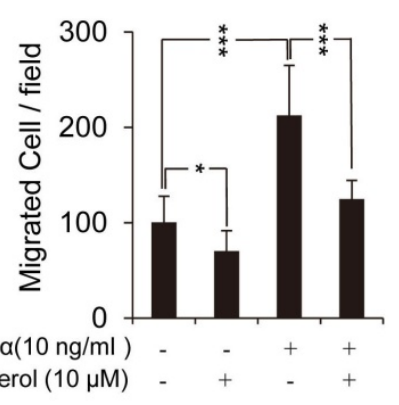

Fig. 4. Inhibitory effects of indacaterol on invasion and migration of human fibrosarcoma cells. (A-B) HT1080 cells $\left(1 \times 10^{5}\right.$ cells per well) were seeded on 24-well plates for $12 \mathrm{~h}$. The medium was changed to DMEM supplemented with $0.1 \%$ FBS (100 units $/ \mathrm{ml}$ penicillin and $100 \mu \mathrm{g} / \mathrm{ml}$ streptomycin). After $16 \mathrm{~h}$, cells were pretreated with indicated concentrations of indacaterol for $2 \mathrm{~h}$ and then treated with TNF- $\alpha(10 \mathrm{ng} / \mathrm{ml})$ for $12 \mathrm{~h}$. Cells that invaded into the bottom side of the filter were stained with crystal violet $(A)$ and the number of cells per field in representative areas was counted under a light microscope at $20 \times$ objective. (B). ${ }^{*} p<0.05$ and ${ }^{* * *} p<0.001$. (C) HT1080 cells $\left(5 \times 10^{4}\right.$ cells $)$ cells were seeded onto both sides of a culture insert (ibidi, Germany). After $16 \mathrm{~h}$, cells were pretreated with $10 \mu \mathrm{M}$ indacaterol for 2 $\mathrm{h}$, the culture insert was carefully removed and $10 \%$ FBS DMEM containing $10 \mathrm{ng} / \mathrm{ml}$ TNF- $\alpha$ was added to the dish. The start position of the cell before movement is indicated by a black dotted line. The cells were then incubated for $8 \mathrm{~h}$. The zones of wound healing and migrated cells were observed using light microscopy (Olympus).

\section{DISCUSSION}

Indacaterol is a once-daily, inhaled, ultra-long-acting ADRB2 agonist recently approved by FDA for the management of pa- tients with COPD (Donohue et al., 2010). Furthermore, growing body of evidence indicates that indacaterol is statistically superior to twice-daily LABAs (salmeterol and formoterol) and oncedaily anticholinergic tiotropium in COPD patients with dyspnea 
(Yorgancioglu, 2012). While indacaterol is an important therapeutic agent for symptom relief in COPD patients, the molecular mechanism of its pharmacological action remains unclear.

To elucidate this mechanism, we focused on the relationships between ADRB2, $\beta$-arrestin, and NF- $\mathrm{BB}$ pathway, since a number of bronchodilation treatments target the activation of ADRB2 and its internalization, mediated by $\beta$-arrestins ( $\beta$-arr1 and -2 ) (Luttrell and Lefkowitz, 2002). Moreover, there is growing evidence that $\beta$-arrestins are involved in NF- $\mathrm{kB}$ signaling (Witherow et al., 2004). $\beta$-arr2 has been shown to directly bind to $I_{\kappa} B \alpha$ and block both phosphorylation and degradation of $I_{\kappa} \mathrm{B} \alpha$, resulting in the inhibition of NF-kB activity (Gao et al., 2004; Luan et al., 2005). Upstream kinases of IKB such as IKKs and NIK (NF-kBinducing kinase) also interact with $\beta$-arrestins to inhibit NF- $\kappa B$ activity (Witherow et al., 2004). Additionally, a recent report showed that $\beta$-arr2 interacting with another GPCR (GPR120 omega-3 fatty acid receptor) can also inhibit NF-kB signaling by sequestering TGF $\beta$-activated kinase 1 (TAK1) binding protein 1 from TAK1 complex (Oh et al., 2010).

Based on these previous findings, we scrutinized the pharmacological action of indacaterol and detected the agonist effect of indacaterol on ADRB2 and $\beta$-arrestins. Furthermore, this agonist effect was found to be primarily mediated by $\beta$-arr2. On the basis of these results, we also inferred that indacaterol may regulate NF- $\mathrm{KB}$ signaling and ameliorate bronchoconstriction.

Previous studies showed that NF- $\mathrm{KB}$ is a therapeutic target in treatment of COPD (Edwards et al., 2009) and that TNF- $\alpha$ (an activator of NF- $\mathrm{KB}$ ) is a key cytokine in a number of inflammatory lung diseases, including asthma and COPD (Matera et al., 2010). TNF- $\alpha / N F-\kappa B$ signaling is therefore believed to play a central role in the pathophysiology of COPD (Churg et al., 2004). In fact, the overexpression of IKK $\beta$ resulted in an increase in both inflammatory mediators and neutrophilic inflammation similar to the conditions observed in COPD (Catley et al., 2005), while the inhibition of IKK $\beta$ in vivo and in vitro reduced TNF- $\alpha$-induced production of MUC5A/C, one of the major components of respiratory mucus (Lora et al., 2005). In this study, we found that TNF- $\alpha$-induced phosphorylation of both IKB $\alpha$ and IKK $\alpha / \beta$ related to NF-kB pathway is suppressed by pretreatment with indacaterol. These results suggest that indacaterol can inhibit the expression of target genes related to COPD and lung cancer by blocking the NF-kB pathway.

Consistent with this speculation, we found that incubation with indacaterol reduces the expression of NF-KB target genes related to COPD and lung cancer, including MMP-9, in human fibrosarcoma (HT1080) and that it also results in the suppression of tumor cell invasion and migration. Previous studies have shown MMP-9 to be a potential drug target for COPD (Muroski et al., 2008), since overexpression of MMP-9 is correlated with lung damage (Chetty et al., 2008), while selective inhibition of MMP-9 prevents smoke-induced increase in small airway wall thickness in a guinea pig model (Churg et al., 2007). Therefore, we investigated whether MMP-9 expression and enzymatic activity are regulated by indacaterol in human fibrosarcoma (HT1080), which express MMP-9 in abundance. We have observed that indacaterol treatment reduces TNF- $\alpha$-induced MMP9 expression on the transcriptional level, resulting in a decrease in MMP-9 enzymatic activity. MMP-9 has been known to play a key role in invasion and metastasis in various tissues, including the lungs (Klein et al., 2004). In accordance with these reports, indacaterol-treated HT1080 cells showed lower invasiveness. This observation suggests that indacaterol can inhibit tumor cell invasion by decreasing both the expression and activity of MMP9 by suppressing IKK/NF-KB activation.

These results collectively suggest that indacaterol could im- prove lung function in treatment of COPD by inhibiting transcription of target genes involved in inflammatory diseases such as MMP-9 via the blockage of NF- $\mathrm{KB}$ activation.

Note: Supplementary information is available on the Molecules and Cells website (www.molcells.org).

\section{ACKNOWLEDGMENTS}

This work was supported by the KRIBB Research Initiative Program (KGM1221312), and National Research Foundation of Korea Grant funded by the Korean Government (35B-2011-1C00033).

\section{REFERENCES}

Ball, D.I., Brittain, R.T., Coleman, R.A., Denyer, L.H., Jack, D., Johnson, M., Lunts, L.H., Nials, A.T., Sheldrick, K.E., and Skidmore, I.F. (1991). Salmeterol, a novel, long-acting beta 2-adrenoceptor agonist: characterization of pharmacological activity in vitro and in vivo. Br. J. Pharmacol. 104, 665-671.

Barnes, P.J., and Pride, N.B. (1983). Dose-response curves to inhaled beta-adrenoceptor agonists in normal and asthmatic subjects. Br. J. Clin. Pharmacol. 15, 677-682.

Catley, M.C., Chivers, J.E., Holden, N.S., Barnes, P.J., and Newton, R. (2005). Validation of IKK beta as therapeutic target in airway inflammatory disease by adenoviral-mediated delivery of dominant-negative IKK beta to pulmonary epithelial cells. Br. J. Pharmacol. 145, 114-122.

Chetty, A., Cao, G.J., Severgnini, M., Simon, A., Warburton, R., and Nielsen, H.C. (2008). Role of matrix metalloprotease-9 in hyperoxic injury in developing lung. Am. J. Physiol. Lung Cell. Mol. Physiol. 295, L584-592.

Churg, A., Wang, R.D., Tai, H., Wang, X., Xie, C., and Wright, J.L. (2004). Tumor necrosis factor-alpha drives $70 \%$ of cigarette smoke-induced emphysema in the mouse. Am. J. Respir. Crit. Care Med. 170, 492-498.

Churg, A., Wang, R., Wang, X., Onnervik, P.O., Thim, K., and Wright, J.L. (2007). Effect of an MMP-9/MMP-12 inhibitor on smokeinduced emphysema and airway remodelling in guinea pigs. Tho$\operatorname{rax} 62,706-713$

Cullum, V.A., Farmer, J.B., Jack, D., and Levy, G.P. (1969). Salbutamol: a new, selective beta-adrenoceptive receptor stimulant. $\mathrm{Br}$. J. Pharmacol. 35, 141-151.

Donohue, J.F., Fogarty, C., Lotvall, J., Mahler, D.A., Worth, H., Yorgancioglu, A., lqbal, A., Swales, J., Owen, R., Higgins, M., et al. (2010). Once-daily bronchodilators for chronic obstructive pulmonary disease: indacaterol versus tiotropium. Am. J. Respir. Crit. Care Med. 182, 155-162.

Edwards, M.R., Bartlett, N.W., Clarke, D., Birrell, M., Belvisi, M., and Johnston, S.L. (2009). Targeting the NF-kappaB pathway in asthma and chronic obstructive pulmonary disease. Pharmacol. Ther. 121, 1-13.

Finlay, G.A., Russell, K.J., McMahon, K.J., D’Arcy E, M., Masterson, J.B., FitzGerald, M.X., and O'Connor, C.M. (1997). Elevated levels of matrix metalloproteinases in bronchoalveolar lavage fluid of emphysematous patients. Thorax 52, 502-506.

Gao, H., Sun, Y., Wu, Y., Luan, B., Wang, Y., Qu, B., and Pei, G. (2004). Identification of beta-arrestin2 as a $G$ protein-coupled receptor-stimulated regulator of NF-kappaB pathways. Mol. Cell 14, 303-317.

Ghosh, S., May, M.J., and Kopp, E.B. (1998). NF-kappa B and Rel proteins: evolutionarily conserved mediators of immune responses. Ann. Rev. Immunol. 16, 225-260.

Hanania, N.A., Chapman, K.R., and Kesten, S. (1995). Adverse effects of inhaled corticosteroids. Am. J. Med. 98, 196-208.

Johnson, M. (2006) Molecular mechanisms of beta(2)-adrenergic receptor function, response, and regulation. J. Allergy Clin. Immunol. 117, 18-24; quiz 25.

Klein, G., Vellenga, E., Fraaije, M.W., Kamps, W.A., and de Bont, E.S. (2004). The possible role of matrix metalloproteinase (MMP)-2 and MMP-9 in cancer, e.g. acute leukemia. Crit. Rev. Oncol. Hematol. 50, 87-100.

Lee, S.U., Choi, Y.H., Kim, Y.S., Park, S.J., Kwak, H.B., Min, Y.K., 
Kim, H.N., Lim, K.E., Choi, J.Y, Rhee, M., et al. (2010). Physcion-8-O-beta-D-glucopyranoside enhances the commitment of mouse mesenchymal progenitors into osteoblasts and their differentiation: Possible involvement of signaling pathways to activate BMP gene expression. J. Cell. Biochem. 109, 1148-1157.

Lee, S.U., In, H.J., Kwon, M.S., Park, B.O, Jo, M., Kim, M.O, Cho, S., Lee, S., Lee, H.J., Kwak, Y.S., et al. (2013). beta-Arrestin 2 mediates $\mathrm{G}$ protein-coupled receptor 43 signals to nuclear Factor-kappaB. Biol. Pharm. Bull. 36, 1754-1759.

Lefkowitz, R.J., and Shenoy, S.K. (2005). Transduction of receptor signals by beta-arrestins. Science 308, 512-517.

Ling, H., Zhang, Y., Ng, K.Y., and Chew, E.H. (2011). Pachymic acid impairs breast cancer cell invasion by suppressing nuclear factorkappaB-dependent matrix metalloproteinase-9 expression Breast Cancer Res. Treat. 126, 609-620.

Loganathan, R.S., Stover, D.E., Shi, W., and Venkatraman, E. (2006). Prevalence of COPD in women compared to men around the time of diagnosis of primary lung cancer. Chest 129, 13051312.

Lora, J.M., Zhang, D.M., Liao, S.M., Burwell, T., King, A.M., Barker P.A., Singh, L., Keaveney, M., Morgenstern, J., Gutierrez-Ramos, J.C. et al. (2005). Tumor necrosis factor-alpha triggers mucus production in airway epithelium through an IkappaB kinase betadependent mechanism. J. Biol. Chem. 280, 36510-36517.

Luan, B., Zhang, Z., Wu, Y., Kang, J., and Pei, G. (2005). Betaarrestin2 functions as a phosphorylation-regulated suppressor of UV-induced NF-kappaB activation. EMBO J. 24, 4237-4246.

Lundblad, L.K., Thompson-Figueroa, J., Leclair, T., Sullivan, M.J., Poynter, M.E., Irvin, C.G., and Bates, J.H. (2005). Tumor necrosis factor-alpha overexpression in lung disease: a single cause behind a complex phenotype. Am. J. Respir. Crit. Care Med. 171 1363-1370.

Luttrell, L.M., and Lefkowitz, R.J. (2002). The role of beta-arrestins in the termination and transduction of G-protein-coupled receptor signals. J. Cell Sci. 115, 455-465.

Matera, M.G., Calzetta, L., and Cazzola, M. (2010). TNF-alpha inhibitors in asthma and COPD: we must not throw the baby out with the bath water. Pulm. Pharmacol. Ther. 23, 121-128.

Muroski, M.E., Roycik, M.D., Newcomer, R.G., Van den Steen, P.E., Opdenakker, G., Monroe, H.R., Sahab, Z.J., and Sang, Q.X (2008). Matrix metalloproteinase-9/gelatinase $B$ is a putative the rapeutic target of chronic obstructive pulmonary disease and multiple sclerosis. Curr. Pharm. Biotechnol. 9, 34-46.

Naline, E., Trifilieff, A., Fairhurst, R.A., Advenier, C., and Molimard, M. (2007). Effect of indacaterol, a novel long-acting beta2-agonist, on isolated human bronchi. Eur. Respir. J. 29, 575-581.

Oh, D.Y., Talukdar, S., Bae, E.J., Imamura, T., Morinaga, H., Fan, W., Li, P., Lu, W.J., Watkins, S.M., and Olefsky, J.M. (2010). GPR120 is an omega-3 fatty acid receptor mediating potent antiinflammatory and insulin-sensitizing effects. Cell 142, 687-698.

Sekine, Y., Katsura, H., Koh, E., Hiroshima, K., and Fujisawa, T. (2012). Early detection of COPD is important for lung cancer surveillance. Eur. Respir. J. 39, 1230-1240.

Shenoy, S.K., and Lefkowitz, R.J. (2003). Multifaceted roles of betaarrestins in the regulation of seven-membrane-spanning receptor trafficking and signalling. Biochem. J. 375, 503-515.

Tashkin, D.P., and Ferguson, G.T. (2013). Combination bronchodilator therapy in the management of chronic obstructive pulmonary disease. Respir. Res. 14, 49

van der Molen, T., Postma, D.S., Turner, M.O., Jong, B.M., Malo, J.L., Chapman, K., Grossman, R., de Graaff, C.S., Riemersma, R.A., and Sears, M.R. (1997). Effects of the long acting beta agonist formoterol on asthma control in asthmatic patients using inhaled corticosteroids. The Netherlands and Canadian formoterol study investigators. Thorax 52, 535-539.

Vestbo, J., Prescott, E., and Lange, P. (1996). Association of chronic mucus hypersecretion with FEV1 decline and chronic obstructive pulmonary disease morbidity. Copenhagen City heart study group. Am. J. Respir. Crit. Care Med. 153, 1530-1535.

Watanabe, T., Jono, H., Han, J., Lim, D.J., and Li, J.D. (2004). Synergistic activation of NF-kappaB by nontypeable Haemophilus influenzae and tumor necrosis factor alpha. Proc. Natl. Acad. Sci. USA 101, 3563-3568

Welte, T. (2009). Optimising treatment for COPD--new strategies for combination therapy. Int. J. Clin. Pract. 63, 1136-1149.

Witherow, D.S., Garrison, T.R., Miller, W.E., and Lefkowitz, R.J. (2004). beta-Arrestin inhibits NF-kappaB activity by means of its interaction with the NF-kappaB inhibitor IkappaBalpha. Proc. Natl. Acad. Sci. USA 101, 8603-8607.

Yorgancioglu, A. (2012). Indacaterol in chronic obstructive pulmonary disease: an update for clinicians. Ther. Adv. Chronic. Dis. 3, 25-36. 